\title{
In Silico Molecular Interaction Studies of Suberoylanilide Hydroxamic Acid and Its Modified Compounds with Histones Deacetylase Class II Homo sapiens as Curative Measure towards Cervical Cancer
}

\author{
Usman Sumo Friend Tambunan $^{1 *}$, Arli Aditya Parikesit ${ }^{1}$, Tirtana Prasetia ${ }^{1}$, Djati Kerami ${ }^{2}$ \\ ${ }^{1}$ Department of Chemistry, Faculty of Mathematics and Science, University of Indonesia, Depok, Indonesia \\ ${ }^{2}$ Department of Mathematics, Faculty of Mathematics and Science, University of Indonesia, Depok, Indonesia \\ Email: "usman@ui.ac.id
}

Received May 2013

\begin{abstract}
The threat of cervical cancer is a serious problem for the women's health. It is already known that the cause of cervical cancer is definitely HPV (Human Papilloma Virus). The drug development is the most reasonable approach for coping with HPV infection. The development of HDACi (Histone Deacetylase inhibitor) is seen as a feasible method for curing the threat of cervical cancer. Rational drug design is our utilized pipeline for drug development. The LigX MOE-based method has been developed to investigate the molecular interaction of HDAC class II Homo sapiens with the designed lead compound. The method has found that ligands 1c, 2a, and 2c are indeed feasible to be formulated as drug candidates.
\end{abstract}

Keywords: Cervical Cancer; HPV; HDAC; SAHA; LigX; Dynamics Simulations

\section{Introduction}

The second most tangible cancer threat for woman is cervical cancer that is caused by Human Papillomavirus (HPV) [1,2]. There are several studies to date that struggling to cope with HPV infection. The possible approaches are developing drugs and vaccine. To date, there are numerous successful projects in HPV vaccine and immunotheraphy development, and some of them already reach the market [3-6]. Moreover, computational approach of designing HPV vaccine is on sight as well [7]. However, the vaccine could only feature as the prevention agent, not curative one. In this end, drug development is seen as one of the most promising methods of curing HPV infection.

There are some anti-HPV drug development methods in the market, but one of the feasible strategies for cervical cancer therapy is the development of Histone deacetylase inhibitor (HDACi) as the drug candidate $[8,9]$. The side effects of SAHA are well known in the medical community by inhibiting immature osteoblasts [10]. Henceforth, the derivatives of SAHA have been developed for mitigating those side effects. Moreover, the possible modification on the SAHA functional groups is basically numerous.

\footnotetext{
"Corresponding author.
}

The objective of this research is to investigate the molecular interaction of our designed ligands, as SAHA modified compounds, with the HDAC class II Homo sapiens. In this end, it is expected that this study will pave a way for developing drug candidates.

\section{Methods}

The whole method was utilized based upon the procedure in $[11,12]$. The 3D structure of Homo sapiens class II HDAC was prepared. The integrity of the protein and ligand structure was optimized with Linux script and Autodock tools [13]. The molecular docking and dynamics procedure were conducted in accordance to the established method [11,12]. The stages of molecular dynamics are initialization, equilibration, and production. In order to study the molecular interaction, the LigX tool of MOE 2008.10 was utilized.

\section{Results and Discussion}

The designated pipeline has eventually produced the desired result. The autodock visualization of the active site of HDAC class II Homo sapiens was shown in Figure 1. It is shown that the active site was hidden in the inner crevice. In this end, a sophisticated pipeline was needed to observe the ligand interaction within the crevice itself. 


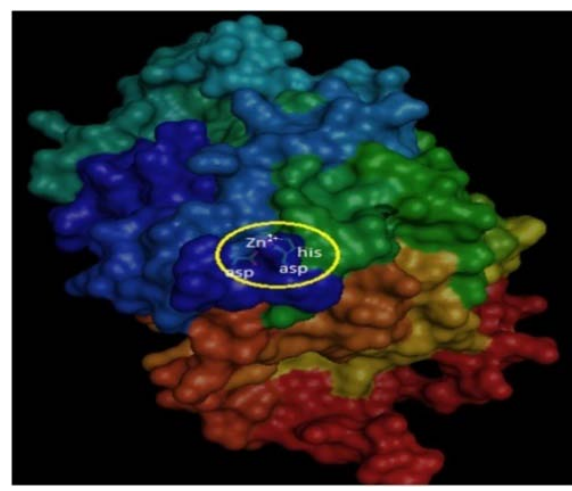

Figure 1. Visualization of the active site of HDAC class II Homo sapiens.

We have prepared the best ligand based upon the previous study that has the best affinity and the lowest toxicity in accordance to the Lipinski's Rule of Five [12,14]. Each HDAC will be paired with SAHA as its standard and one best ligand in order to observe their molecular interaction. The interaction pair between ligand and HDAC could be observed in Table 1.

The existing drug development pipeline has designed three SAHA-derived ligands, namely 1c, 2a, and 2c [11], [12]. LigX, as an integrated tool of MOE packages, has been utilized by scientific community to evaluate the structure-based ligand optimization. The Figure 1 shows that the $\mathrm{Zn}^{2+}$ ion interaction with existing residues is stronger in our ligand than SAHA. Thus, it is a direct evidence that metal-based cofactor plays a role in the protein-ligand interaction [15]. The electron distribution of our ligands is more favorable than the standard, as shown in all instances of Figure 2, because the electron cloud is distributed more equally in all atoms of our ligands. Observation of contact residues and hydrogen bonding of those ligands have shown that they are indeed suitable to be developed as HDACi, as the molecular interaction is stronger than SAHA.

\section{Conclusion}

The computational effort of this study has shown that the electronic interaction of the ligand with the receptor is the main factor for the well being of a chemical reaction. The molecular interaction study has shown that our ligands are indeed feasible to be developed as drug candi-
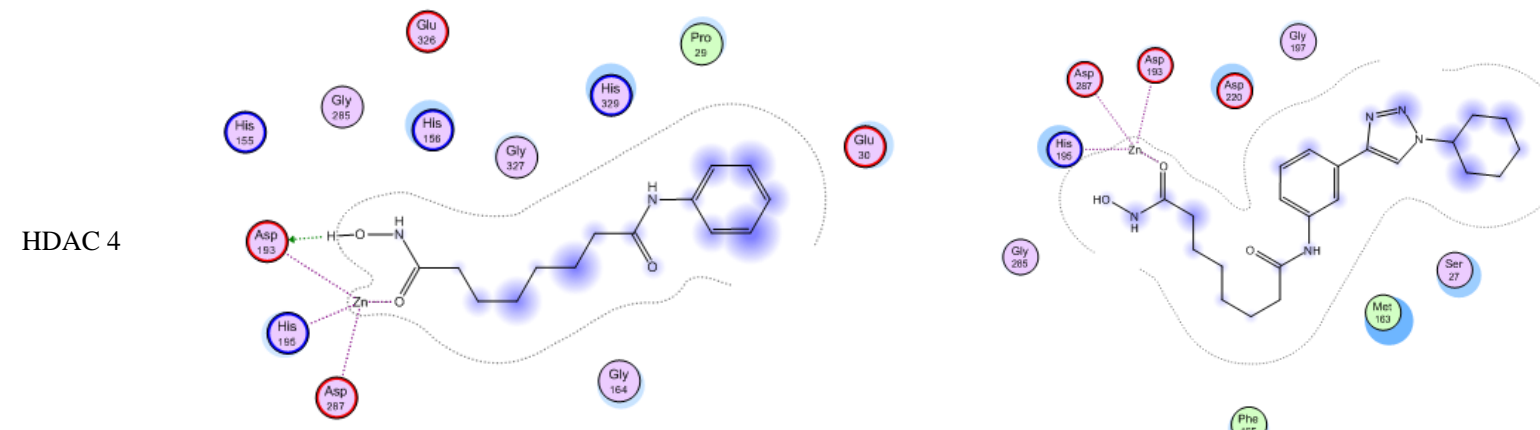

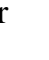


HDAC 6
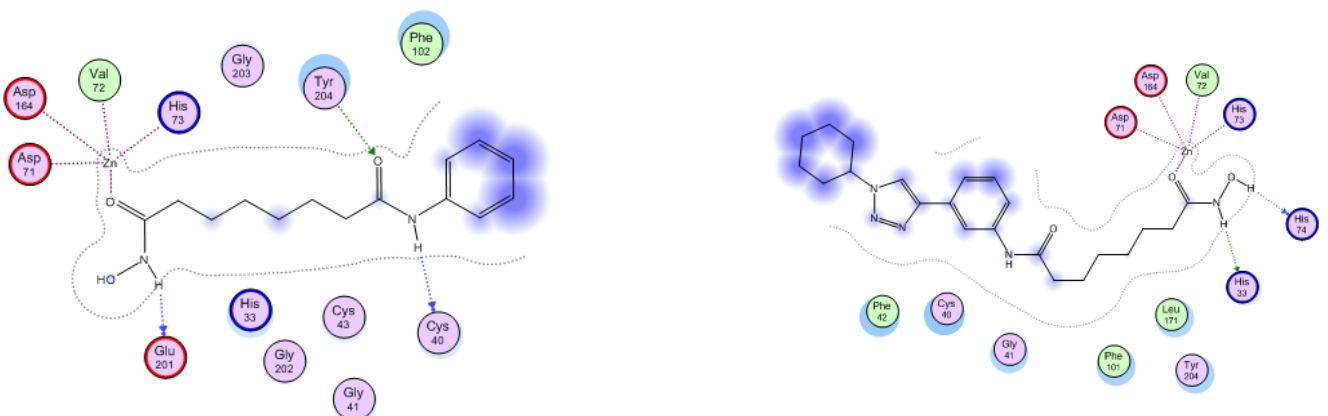

(e)

(f)

HDAC 7

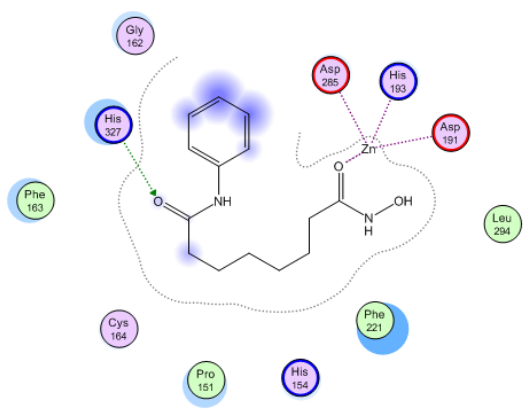

(g)

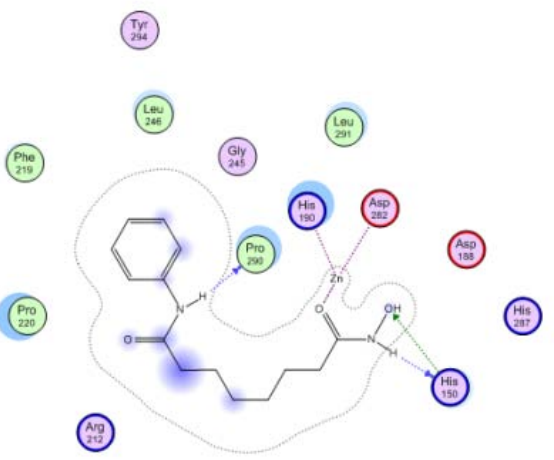

(i)

Figure 2. The molecular interaction visualization of LigX tools after molecular dynamics production session at 5000 ps for: (a) HDAC4-SAHA; (b) HDAC4-2c; (c) HDAC5-SAHA; (d) HDAC5-2a; (e) HDAC6-SAHA; (f) HDAC6-2c; (g) HDAC7-SAHA; (h) HDAC7-2c; (i) HDAC9-SAHA; (j) HDAC9-1c.

Table 1. The HDAC class II Homo sapiens pairing with the ligand.

\begin{tabular}{ccc}
\hline Enzim & \multicolumn{2}{c}{ Ligan } \\
\hline HDAC 4 & SAHA & 2c \\
HDAC 5 & SAHA & 2a \\
HDAC 6 & SAHA & 2c \\
HDAC 7 & SAHA & 2c \\
HDAC 9 & SAHA & 1c \\
\hline
\end{tabular}

dates due to their strong affinities with the receptors.

\section{Acknowledgements}

The funding for the research and the conference is sup- ported by Skema Bantuan Seminar Luar Negeri/Program Insentif Peneliti Universitas Indonesia Tahun 2013 (BOPTN) Submission \#1511 and Hibah BOPTN Ditjen Dikti No: 2788/H2.R12/HKP.05.00/2013. Usman Sumo Friend Tambunan and Djati Kerami supervised this research; Tirtana Prasetia was working on the technical details, while Arli Aditya Parikesit prepared the English manuscript and re-verified the computation data.

\section{REFERENCES}

[1] M. H. Schiffman, H. M. Bauer, R. N. Hoover, A. G. Glass, D. M. Cadell, B. B. Rush, D. R. Scott, M. E. Sherman, R. J. Kurman, S. Wacholder, C. K. Stanton and M. M. Manos, "Epidemiologic Evidence Showing That Human Papillomavirus Infection Causes Most Cervical 
Intraepithelial Neoplasia,” Journal of the National Cancer Institute, Vol. 85, No. 12, 1993, pp. 958-964. http://dx.doi.org/10.1093/jnci/85.12.958

[2] WHO, “Cervical Cancer Summary Report,” 2010.

[3] K. E. Palmer, A. B. Jenson, J. C. Kouokam, A. B. Lasnik and S. Ghim, "Recombinant Vaccines for the Prevention of Human Papillomavirus Infection and Cervical Cancer," Experimental and Molecular Pathology, Vol. 86, No. 3, 2009, pp. 224-233. http://dx.doi.org/10.1016/j.yexmp.2009.01.009

[4] J. A. Kahn, "HPV Vaccination for the Prevention of Cervical Intraepithelial Neoplasia,” The New England Journal of Medicine, Vol. 361, No. 3, 2009, pp. 271-278. http://dx.doi.org/10.1056/NEJMct0806938

[5] D. R. Lowy and J. T. Schiller, "Prophylactic Human Papillomavirus Vaccines,” The Journal of Clinical Investigation, Vol. 116, No. 5, 2006, pp. 1167-1173. http://dx.doi.org/10.1172/JCI28607

[6] S. Kanodia, D. M. Da Silva and W. M. Kast, "Recent Advances in Strategies for Immunotherapy of Human Papillomavirus-Induced Lesions," International Journal of Cancer. Journal International du Cancer, Vol. 122, No. 2, 2008, pp. 247-259.

[7] U. S. F. Tambunan, D. Sugiono, T. A. Tochary and A. A. Parikesit, "Computational Study of Post Translation Modification in Chimeric Virus Like Particles Vaccine of Human Papilloma Virus with Virion Capsid L1,” Makara Seri Sains, Vol. 11, 2007.

[8] B. E. Gryder, Q. H. Sodji and A. K. Oyelere, "Targeted Cancer Therapy: Giving Histone Deacetylase Inhibitors All They Need To Succeed,” Future Medicinal Chemistry, Vol. 4, No. 4, 2012, pp. 505-524.

[9] T. G. Edwards, K. J. Koeller, U. Slomczynska, K. Fok, M.
Helmus, J. K. Bashkin and C. Fisher, "HPV Episome Levels Are Potently Decreased by Pyrrole-Imidazole Polyamides,” Antiviral Research, Vol. 91, No. 2, 2011, pp. 177-186. http://dx.doi.org/10.1016/j.antiviral.2011.05.014

[10] M. E. McGee-Lawrence, A. L. McCleary-Wheeler, F. J. Secreto, D. F. Razidlo, M. Zhang, B. A. Stensgard, X. Li, G. S. Stein, J. B. Lian and J. J. Westendorf, "Suberoylanilide Hydroxamic Acid (SAHA; Vorinostat) Causes Bone Loss by Inhibiting Immature Osteoblasts,” Bone, Vol. 48, No. 5, 2011, pp. 1117-1126. http://dx.doi.org/10.1016/j.bone.2011.01.007

[11] U. S. F. Tambunan and E. K. Wulandari, "Identification of a Better Homo sapiens Class II HDAC Inhibitor through Binding Energy Calculations and Descriptor Analysis,” BMC Bioinformatics, Vol. 11, Suppl. 7, 2010, p. S16. http://dx.doi.org/10.1186/1471-2105-11-S7-S16

[12] U. S. F. Tambunan, N. Bramantya and A. A. Parikesit, "In Silico Modification of Suberoylanilide Hydroxamic Acid (SAHA) as Potential Inhibitor for Class II Histone Deacetylase (HDAC),” BMC Bioinformatics, Vol. 12 Suppl. 1, 2011, p. S23.

[13] G. M. Morris, R. Huey and A. J. Olson, "Using AutoDock for Ligand-Receptor Docking,” In: A. D. Baxevanis, et al., Eds., Current Protocols in Bioinformatics/Editoral Board, Vol. Chapter 8, Unit 8.14, 2008.

[14] C. A. Lipinski, F. Lombardo, B. W. Dominy and P. J. Feeney, "Experimental and Computational Approaches to Estimate Solubility and Permeability in Drug Discovery and Development Settings," Advanced drug delivery Reviews, Vol. 46, No. 1-3, 2001, pp. 3-26. http://dx.doi.org/10.1016/S0169-409X(00)00129-0

[15] W. Kaim and B. Schwederski, "Bioinorganic Chemistry," Wiley, 1994. 